\title{
Avaliação do processo de implementação do Plano Nacional da Sociobiodiversidade na mesorregião do Bico do Papagaio
}

Lucélia Neves dos Santos

Mestre pelo Programa de Pós-Graduação em Desenvolvimento Regional da Universidade Federal do Tocantins

$W$ aldecy Rodrigues

Programa de Pós-Graduação em Desenvolvimento Regional da Universidade Federal do Tocantins (Uft)

Recebido: 23/11/2015 Versão revisada (entregue): 02/03/2016 Aprovado: 09/03/2016

\begin{abstract}
Resumo
O Plano Nacional para Promoção das Cadeias de Produtos da Sociobiodiversidade (PNPSB) tem como objetivo promover e fortalecer as cadeias dos produtos da sociobiodiversidade brasileira, com agregação de valor e consolidação de mercados sustentáveis. O presente trabalho avaliou o processo de implementação do PNPSB, investigando a sua efetividade no fortalecimento da cadeia produtiva do coco de babaçu, no âmbito da mesorregião do Bico do Papagaio, estado do Tocantins. Para tanto, foi utilizada a técnica Delphi de Políticas na aplicação de questionários aos atores envolvidos (movimentos sociais, comunidades extrativistas e setor público). A pesquisa revelou as discussões existentes no âmbito da implementação desta política acerca do acesso limitado às informações por parte das comunidades extrativistas, a participação dos extrativistas nas ações do Plano, a sua execução num período regular e o processo de industrialização do coco de babaçu pelos extrativistas. É fundamental que os condutores do PNPSB reconheçam as questões citadas pelos atores sociais envolvidos e desenvolvam a implementação por estes almejada.
\end{abstract}

Palavras-chave | Bico do Papagaio; comunidades extrativistas; desenvolvimento; Plano Nacional para Promoção das Cadeias de Produtos da Sociobiodiversidade.

Código JEL | O13; Q56; Q58.

\section{EVALUATION OF THE IMPLEMENTATION PROCESS ON THE NATIONAL PLAN FOR SOCIO-BIODIVERSITY IN THE MESOREGION BICO DO PAPAGAIO, BRAZIL}

\begin{abstract}
The National Plan for the Promotion of Socio-biodiversity Chain Products (PNPSB) aims to promote and strengthen the bonds of Brazilian biodiversity's products, with value added and consolidation of sustainable markets. This study evaluated the PNPSB's implementation
\end{abstract}


process, investigating its effectiveness in strengthening the Babassu's productive chain, within the middle region of the Bico do Papagaio (TO). For this, the Delphi technique in the Policy application of questionnaires was used to stakeholders (Social Movements, Communities and Public Sector). The survey revealed the existing discussions in the implementation of this policy about the limited access to information by the extractive communities, the participation in the actions of the Plan, its implementation in a regular period and the industrialization process of babassu by extractive. Thus, it is critical that PNPSB drivers recognize the issues raised by the involved social actors and develop the implementation of these desired for them.

Keywords | Bico do Papagaio; development; extractive communities; National Plan for Sociobiodiversity.

JEL-Code | O13; Q56; Q58.

\section{EVALUACIÓN DEL PROCESO DE IMPLEMENTACIÓN DEL PLAN NACIONAL DE LA BIODIVERSIDAD EN LA REGIÓN DEL BICO DO PAPAGAIO, BRASIL}

\section{Resumen}

El Plan Nacional para la Promoción de las Cadenas de Productos de la Sociobiodiversidad (PNPSB) tiene como meta promover y fortalecer las cadenas de productos de la biodiversidad, con la agregación de valor y consolidación de mercados sostenibles. El presente estudio evaluó el proceso de implementación de la PNPSB, investigando su eficacia en el fortalecimiento de la cadena productiva del coco de babasú, en la región del Bico do Papagaio. Para eso fue utilizada la técnica Delphi de Políticas en la aplicación de cuestionarios a los actores involucrados (movimientos sociales, comunidades extractivas y el sector público). La investigación reveló las discusiones existentes en el ámbito de la implementación de esta política acerca del limitado acceso a las informaciones por parte de las comunidades extractivistas, la participación de los extractivistas en las acciones del Plan, su ejecución en un período regular y el proceso de industrialización de coco babasú por los extractivistas. Es fundamental que los coordinadores del PNPSB reconozcan las cuestiones planteadas por los actores sociales involucrados y desarrollen la implementación deseada por estos.

Palabras-clave | Bico do Papagaio; comunidades extractivistas; desarrollo; Plan Nacional para la Promoción de las Cadenas de Productos de la Sociobiodiversidad.

Código JEL | O13; Q56; Q58.

\section{Introdução}

O presente trabalho avaliou o processo de implementação do Plano Nacional para Promoção das Cadeias de Produtos da Sociobiodiversidade (PNPSB) e teve como propósito verificar o alcance desta política pública para as comunidades extrativistas do coco de babaçu. O PNPSB tem como objetivo principal desenvolver ações integradas com outras políticas públicas para promover e fortalecer as cadeias dos produtos da sociobiodiversidade brasileira, com agregação de valor e consolidação de mercados sustentáveis. O referido Plano encontra-se em fase de implementação e inicialmente foi explorada a cadeia 
produtiva do coco de babaçu e da castanha do Brasil, que, juntas, incluem cerca de 500 mil famílias entre quebradeiras de coco e extrativistas, e geram aproximadamente $\mathrm{R} \$ 160$ milhões/ano para a economia brasileira.

Para avaliar o processo de implementação deste Plano o método Delphi de Políticas foi utilizado na aplicação de questionários para os atores envolvidos (representantes das comunidades extrativistas, dos movimentos sociais e os condutores do PNPSB). No processo de avaliação de política pública foi enfocada uma modalidade específica: a avaliação de processos. Essa avaliação possibilitará medir o efeito de algumas ações desta política para os seus beneficiários, sejam eles membros de comunidades agroextrativistas ou de movimentos sociais que ainda não dispõem de equipamentos para desenvolver processos industrializados.

Nesse sentido, serão apresentados conceitos básicos como a definição de avaliação e a especificação de cada modalidade adotada e, na sequência, a caracterização da área percorrida para realizar a pesquisa, assim como o seu resultado.

As considerações finais demonstram o resultado e a expectativa dos atores sociais envolvidos na implementação do PNPSB e o que este representa ou poderá representar na sustentabilidade socioambiental do extrativismo do coco de babaçu, sugerindo assim uma reflexão sobre as potencialidades da pesquisa de avaliação de políticas públicas.

\section{A avaliação do processo em políticas públicas}

De acordo com Rua (1997), "a política consiste no conjunto de procedimentos formais e informais que expressam relações de poderes que se destinam à resolução pacífica dos conflitos quanto a bens públicos". No processo de construção das políticas públicas, a avaliação tem fundamental importância, devido mensurar qual a relevância de uma política para seus beneficiários e de gerar informações com frequência para monitorar a sua execução. Os tipos de avaliação estão divididos em: avaliação ex-ante, avaliação de processo, avaliação de resultado, avaliação de impacto e meta-avaliação. No universo de políticas públicas, o processo de avaliação é caracterizado como "a análise crítica do programa [...] com o objetivo de aprender [...] em que medida as metas estão sendo alcançadas, a que custo, quais os processos ou efeitos colaterais que estão sendo ativados." (LIMA JUNIOR, et al. 1978, p. 4-5).

Considera-se, nesta pesquisa, a avaliação de processo, razão que leva verificar junto aos atores envolvidos no PNPSB como está ocorrendo o processo de implementação das ações do referido Plano e conferir a sua efetividade no fortalecimento da cadeia produtiva do babaçu na mesorregião do Bico do Papagaio. "A avaliação de processos visa à aferição da eficácia: se o programa está sendo (ou foi) implementado de acordo com as diretrizes concebidas para a sua 
execução e seu produto atingirá (ou atingiu) as metas desejadas." (FIGUEIREDO, A.; FIGUEIREDO, M., 2010 p. 110).

\section{Material e métodos}

\section{Método Delphi}

A pesquisa em questão buscou elementos através do método Delphi, o qual consulta um grupo de especialistas a respeito de eventos futuros através de um questionário que é repassado continuadas vezes, até seja obtida uma convergência das respostas (WRIGHT; GIOVINAZZO, 2000). Portanto, o mesmo questionário deve ser encaminhado no mínimo duas vezes aos respondentes, isto é uma particularidade do Delphi e as suas características principais são manter o anonimato dos painelistas, apresentar estatisticamente os resultados, assim como dar a realimentação das respostas ao grupo para reavaliação nas rodadas de questionários seguintes.

O método Delphi possui as seguintes etapas: i) elaboração do questionário para primeira rodada; ii) seleção dos painelistas ou respondentes, distribuindo de forma equilibrada as entidades de interesse; iii) contato com os painelistas para explicar o método, o objetivo da pesquisa e enfatizar a importância da participação; iv) envio do questionário por meio eletrônico ou correio; v) tabulação e análise dos dados da primeira rodada, incorporação ou não de novas questões na segunda rodada; vi) elaboração da segunda rodada do questionário Delphi com apresentação obrigatória do resultado do primeiro questionário aos respondentes para que o mesmo reveja seu posicionamento e envio.

Nos dias atuais, o método Delphi passou a ser bastante conhecido como Policy Delphi (Delphi de Políticas), em função de ser considerado como uma técnica de apoio à decisão e à definição de políticas. Neste sentido, é recomendado quando não se dispõe de dados quantitativos, como no caso da avaliação do processo de implementação das ações do PNPSB.

\section{Procedimentos empíricos}

O método Delphi foi utilizado nesta pesquisa para verificar o alcance do Plano Nacional da Sociobiodiversidade, sendo que a mesma foi estabelecida em duas partes: a primeira tratou-se do planejamento e da elaboração de listagens dos participantes para a aplicação do questionário e a segunda parte foi, de fato, a 
aplicação de duas rodadas dos questionários, os resultados foram adquiridos a partir do consenso de opiniões entre os participantes.

Para a aplicação do método Delphi foi selecionado um grupo de especialistas que representam significativamente os atores sociais envolvidos na implementação do PNPSB. Este grupo foi dividido em duas categorias, uma representada pelos seguintes movimentos sociais: Grupo Produtivo da Comunidade de Juverlândia, ligado a ASMUBIP, MIQCB, APA-TO, COAPIMA, CENTRU-MA. A outra, representada por instituições públicas estaduais e federais que são os condutores dessa política pública: MDA, MMA (ICMBio), EMBRAPA COCAIS, SEAGROTO, SETAS-TO, AGERP-MA. Os resultados oriundos dessa pesquisa permitiu analisar os dados com o intuito de avaliar o processo de implementação do referido Plano na mesorregião do Bico do Papagaio.

Na fase de aplicação do método Delphi, na primeira rodada o questionário foi enviado, com uma carta esclarecendo os objetivos da pesquisa, para 37 representantes do setor público (condutores do PNPSB) e dos movimentos sociais, responsáveis pela implantação do Plano na mesorregião do Bico do Papagaio. Na segunda rodada, o questionário foi reenviado com o resultado da primeira rodada aos representantes das referidas instituições e movimentos sociais, partindo-se do princípio de que optar por esse universo seria a forma de adquirir as informações precisas, em função das suas experiências empíricas e opiniões pessoais. Assim, dos 37 questionários enviados na primeira rodada, 22 foram respondidos e devolvidos; para a segunda rodada foram enviados 22 questionários, dos quais foram obtidos o retorno de $80 \%$.

A bibliografia de referência aponta o número de 15 a 30 respondentes como suficiente para adquirir um retorno satisfatório e relevante em termos de informações (WRIGHT; GIOVINAZZO, 2000). A análise dos dados foi realizada pela estatística descritiva. Os resultados apresentados a seguir foram baseados nos 20 questionários devolvidos na última rodada e as respostas de cada categoria foram analisadas com o objetivo de verificar o alcance do programa para a população alvo.

Por fim, foram colhidas, através de entrevistas de campo, impressões das lideranças comunitárias e atores institucionais sobre as contingências e oportunidades relacionadas à política, e, principalmente, sugestões para sua melhor implementação. 


\section{Resultados e discussões}

\section{Caracterização da área de ocorrências dos babaçuais}

Na mesorregião do Bico do Papagaio (Tocantins, Pará e Maranhão), a ocorrência da palmeira Orbignyaspp, conhecida como babaçu, representa grande apelo social, econômico e ambiental por meio do extrativismo do coco, que oferece ocupação econômica e social para milhares de famílias, além dos babaçuais contribuírem para a redução da emissão de gases de efeito estufa. No livro Palmeiras em Chamas, May (1990) conclui que não reconhecer a utilidade de espécies naturais, como a palmeira de babaçu, assim como a função do extrativista, significa ignorar o potencial desses recursos no processo de desenvolvimento.

\section{Ilustração 1 Área de Ocorrência dos Babaçuais}

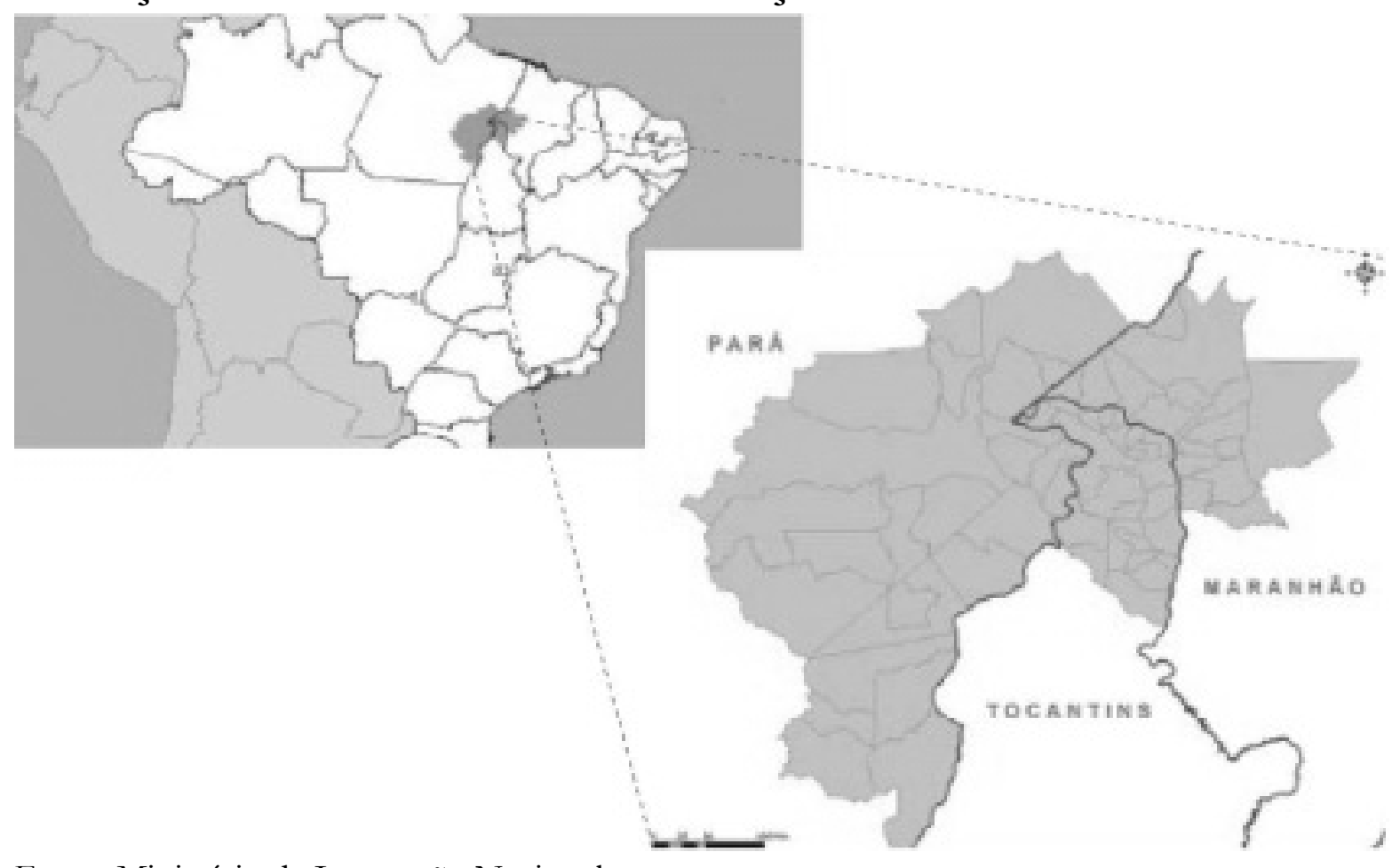

Fonte: Ministério da Integração Nacional.

Geralmente a exploração do babaçu é feita nas entressafras de outras culturas, o que contribui para o aproveitamento da mão de obra local e, consequentemente, atenua o êxodo rural. É necessário também ressaltar que o babaçu é uma palmeira cujo porte possibilita o aproveitamento de espaço para o desenvolvimento de outras culturas alimentares, tornando assim uma determinada localidade em campo produtivo. 
As comunidades que trabalham com a cata e quebra do coco babaçu, através de associações, cooperativas, ONGs (entre outras), demandam acompanhamento e orientação que possam promover e fortalecer essa cadeia produtiva, o uso racional do coco e a conservação da palmeira, pois o babaçu possibilita várias alternativas que abrangem os aspectos socioeconômicos e ambientais. Sendo estes fundamentais para o surgimento de investimentos através de instituições públicas e privadas, nacionais e internacionais, comprometidas com a sustentabilidade da mesorregião do Bico do Papagaio e que ainda favoreça o desenvolvimento dessa região com a implementação de políticas públicas considerando os aspectos culturais, sociais, econômicos e ambientais da Amazônia Legal.

\section{Avaliação do Plano Nacional para Promoção das Cadeias de Produtos da Sociobiodiversidade (PNPSB)}

\section{Gráfico 1 Opinião dos painelistas sobre o nível de conhecimento do Plano}

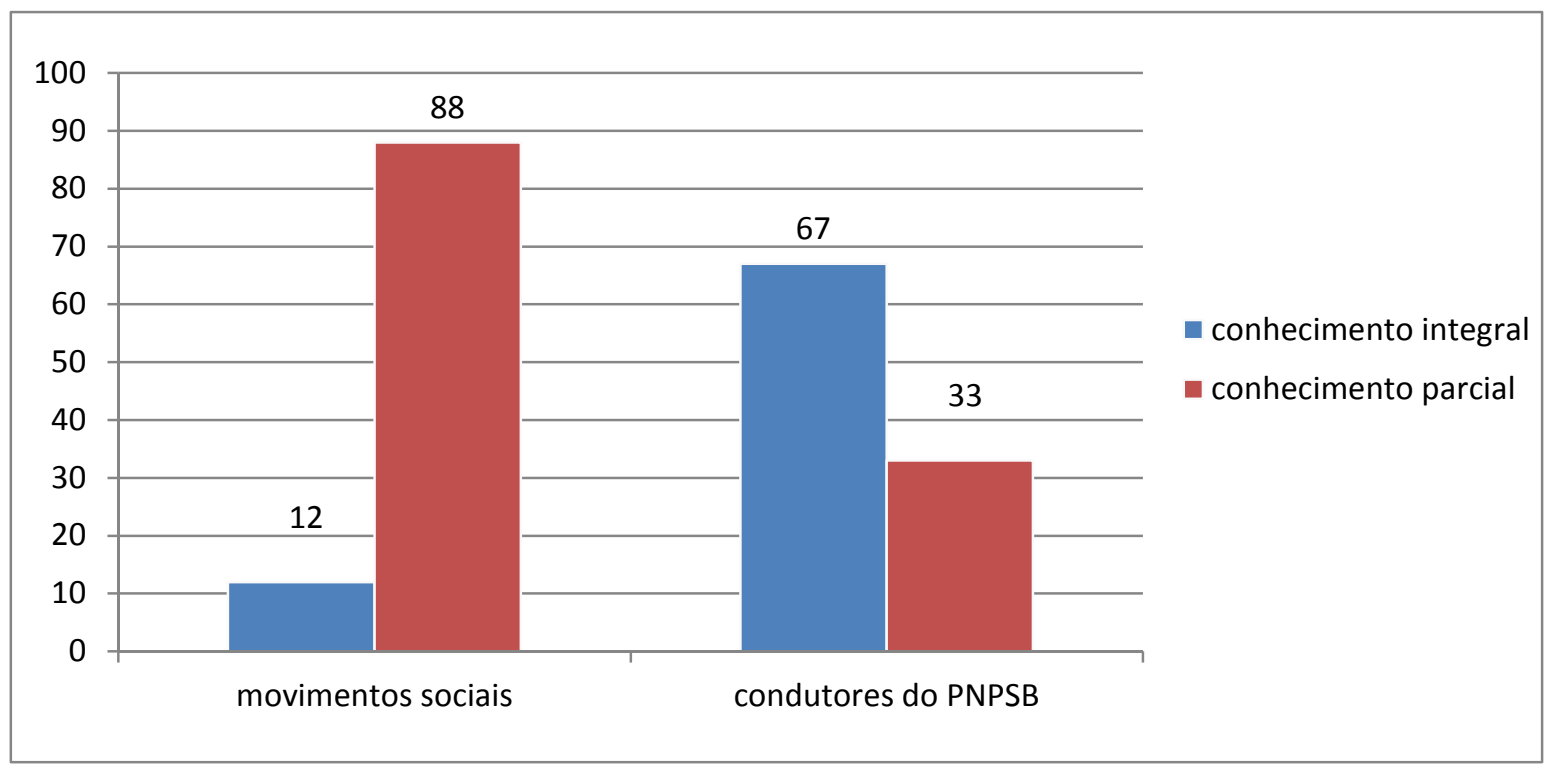

Fonte: Pesquisa de campo.

Em relação ao nível de conhecimento do Plano, 12\% dos painelistas representantes dos movimentos sociais o conhecem integralmente e $88 \%$ o conhecem parcialmente. Esta categoria enfatizou a importância da articulação da sociedade civil organizada na implementação de políticas públicas voltadas para comunidades tradicionais, bem como, a conservação dos recursos naturais. E 67\% dos painelistas que representam os condutores dessa política, informaram que o conhecem integralmente e $33 \%$ informaram conhecer parcialmente, estes colocaram a necessidade de ampliar a divulgação do Plano para as comunidades mais distantes. 
Gráfico 2 Opinião dos painelistas sobre o objetivo geral do Plano

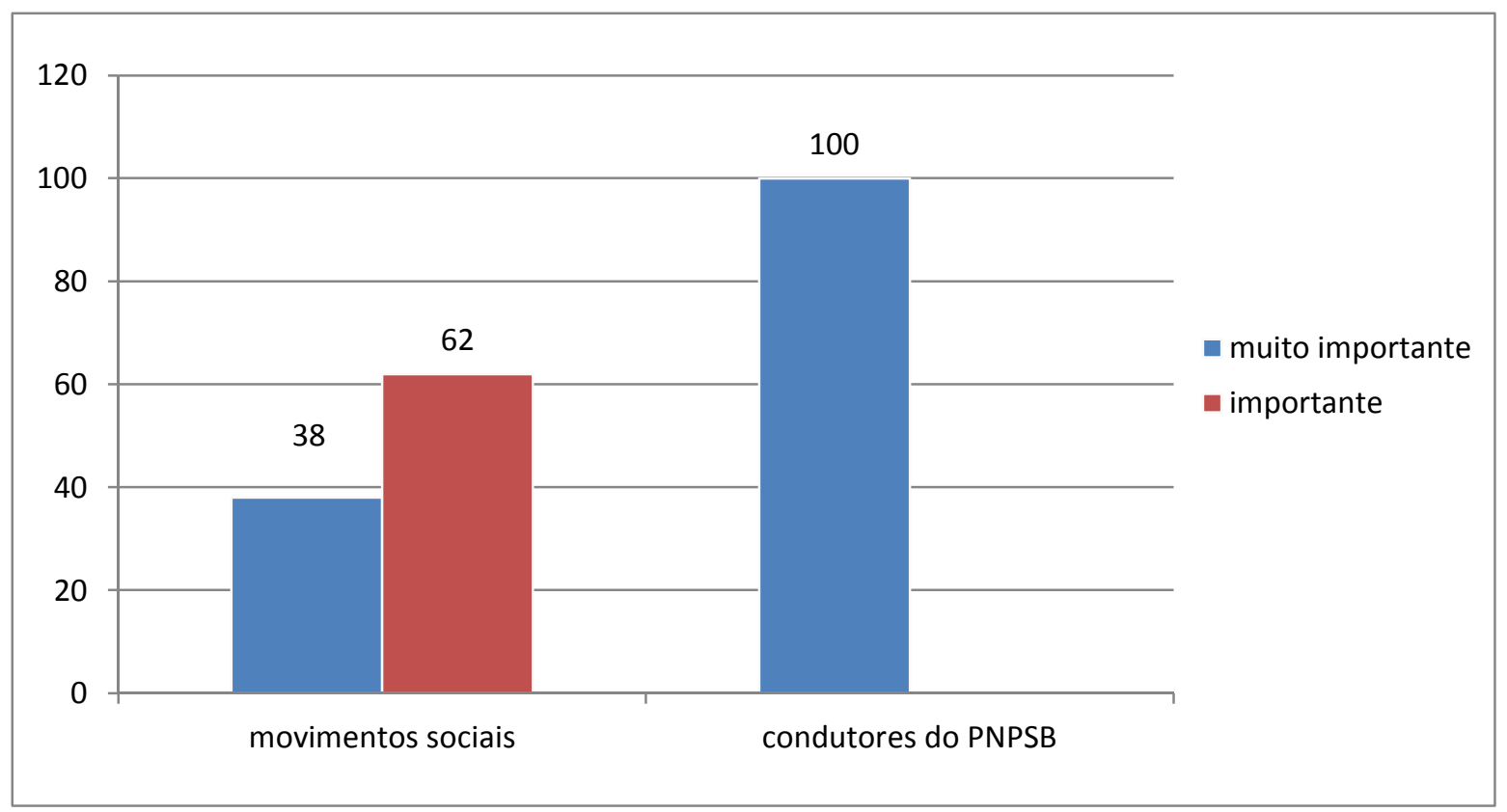

Fonte: Pesquisa de campo.

Quanto ao objetivo do Plano, 38\% dos painelistas representantes dos movimentos sociais o consideram muito importante e $62 \%$ importante. Entretanto, enfatizaram que suas ações precisam de fato se concretizar para que aconteça o fortalecimento do mercado com produtos da sociobiodiversidade. E 100\% dos condutores informaram que consideram o Plano muito importante. De modo geral, considerações em relação aos impactos positivos na qualidade de vida dos Povos, Comunidades Tradicionais e Agricultores Familiares (PCTAF), uso sustentável dos recursos naturais, a consolidação de mercados sustentáveis e a rica diversidade biológica do planeta foram bastantes presentes nos comentários. 
Gráfico 3 Opinião dos painelistas sobre o recebimento de informações sobre as ações do Plano aos movimentos sociais, comunidades agroextrativistas, ONGS, Instituições Públicas e Privadas

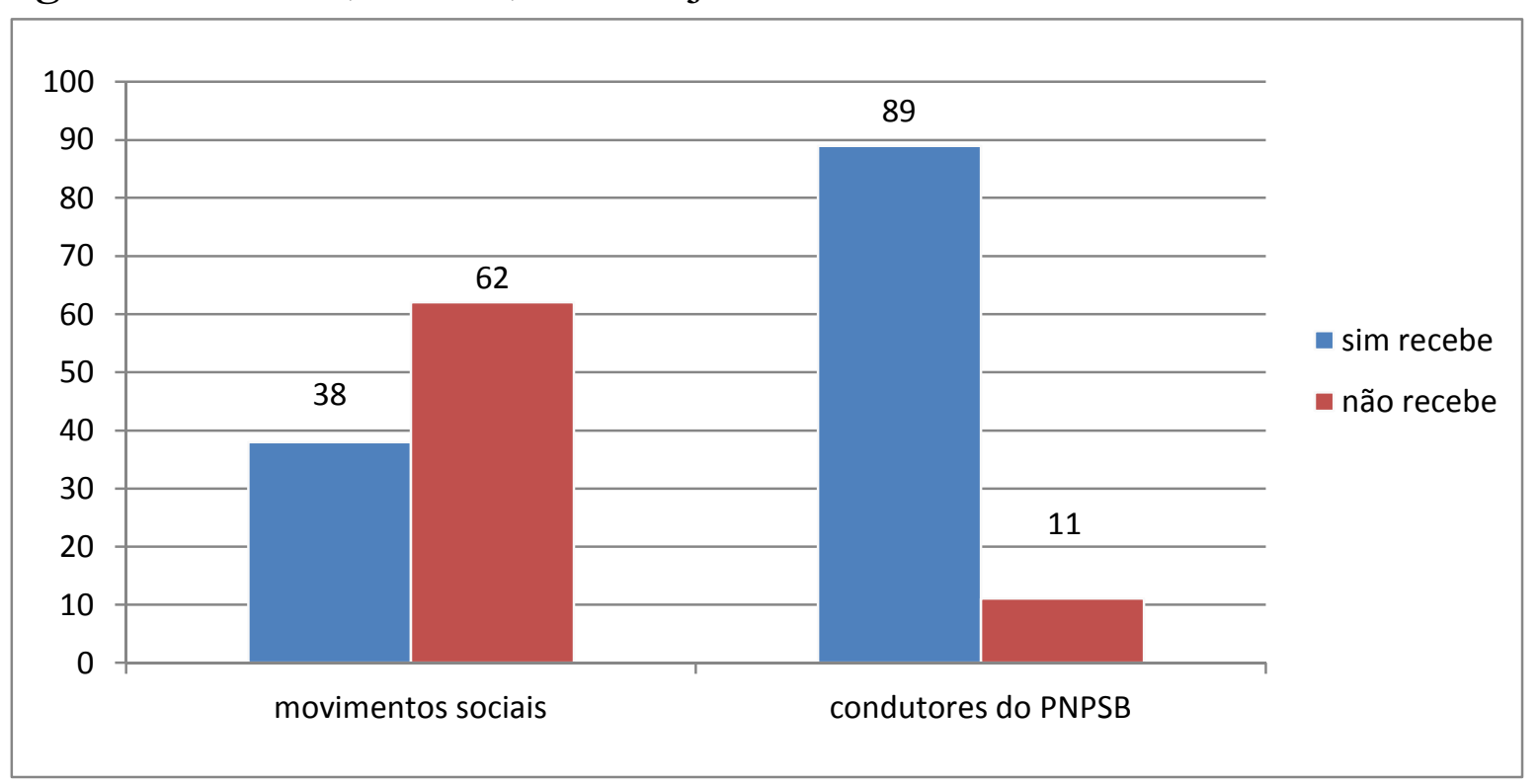

Fonte: Pesquisa de campo.

Os representantes dos movimentos sociais apontam um percentual de $38 \%$ em relação ao recebimento de informações sobre as atividades/ações do Plano e 62\% declaram que estas informações chegam atrasadas devido ao distanciamento que as políticas públicas têm dos trabalhos das organizações sociais. Por vezes, quando chega a informação sobre um evento, o mesmo já aconteceu. $\mathrm{Na}$ opinião dos condutores, $89 \%$ indicaram que recebem estas informações e $11 \%$ que não as recebem em suas instituições. Em alguns comentários, reconheceram as dificuldades que algumas organizações sociais têm para acessar essas informações, daí a necessidade de fazer uma divulgação mais abrangente. 
Gráfico 4 Opinião dos painelistas referente às diretrizes do Plano atender ou não as necessidades das comunidades extrativistas envolvidas

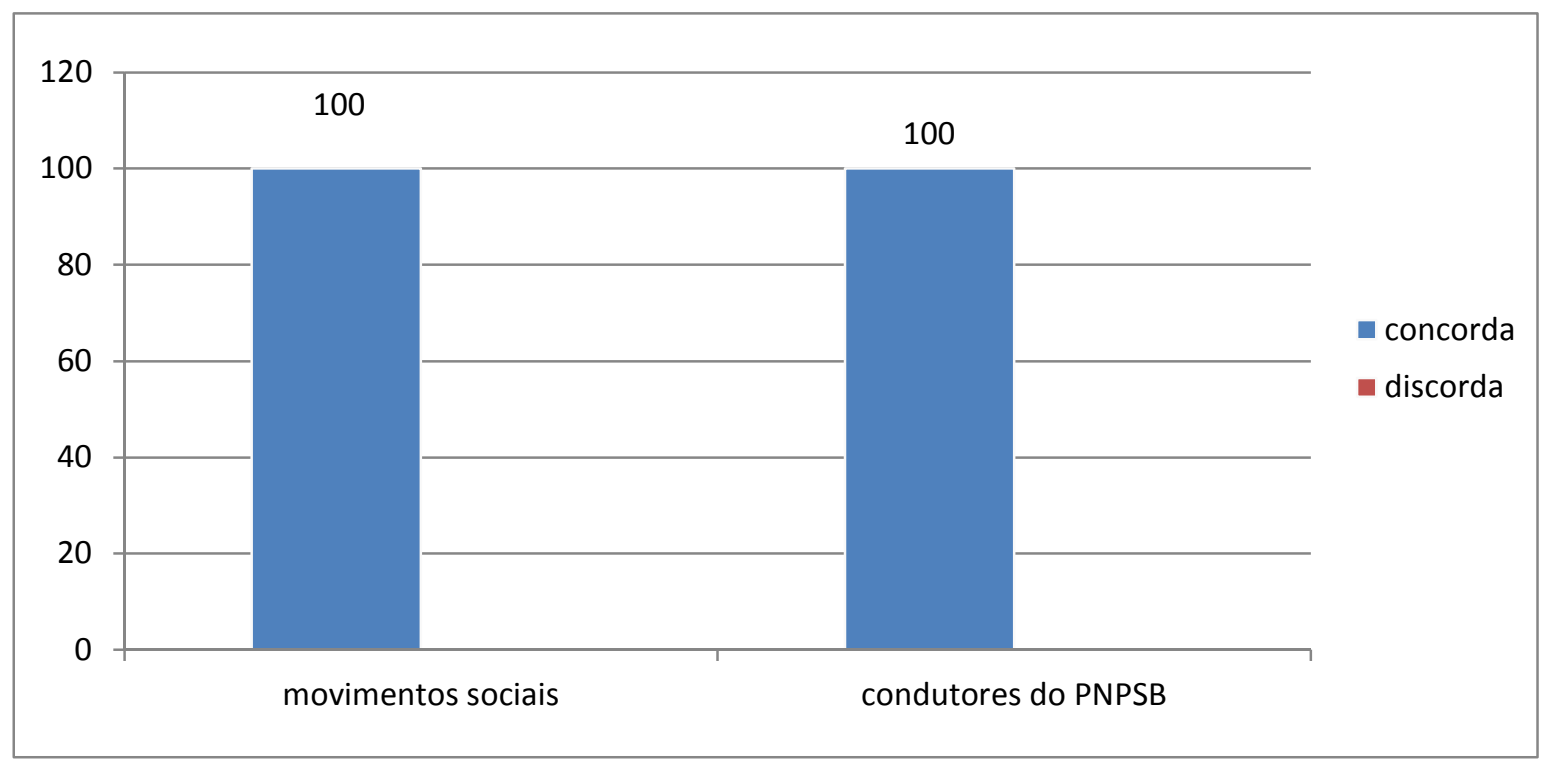

Fonte: Pesquisa de campo.

A pesquisa apontou que 100\% dos movimentos sociais envolvidos concordam com as diretrizes estabelecidas neste Plano, desde que se concretizem e sejam implementadas de fato, e atendem as necessidades das comunidades extrativistas. Do mesmo modo, $100 \%$ dos condutores do PNPSB concordaram com essas diretrizes, e, ainda, alguns lembraram que estas foram definidas com base em seminários regionais e nacional, envolvendo mais de 700 pessoas, e que tiveram o foco no atendimento às necessidades apresentadas pelas comunidades extrativistas. 


\section{Gráfico 5 Opinião dos painelistas sobre a execução do plano em prazo regular}

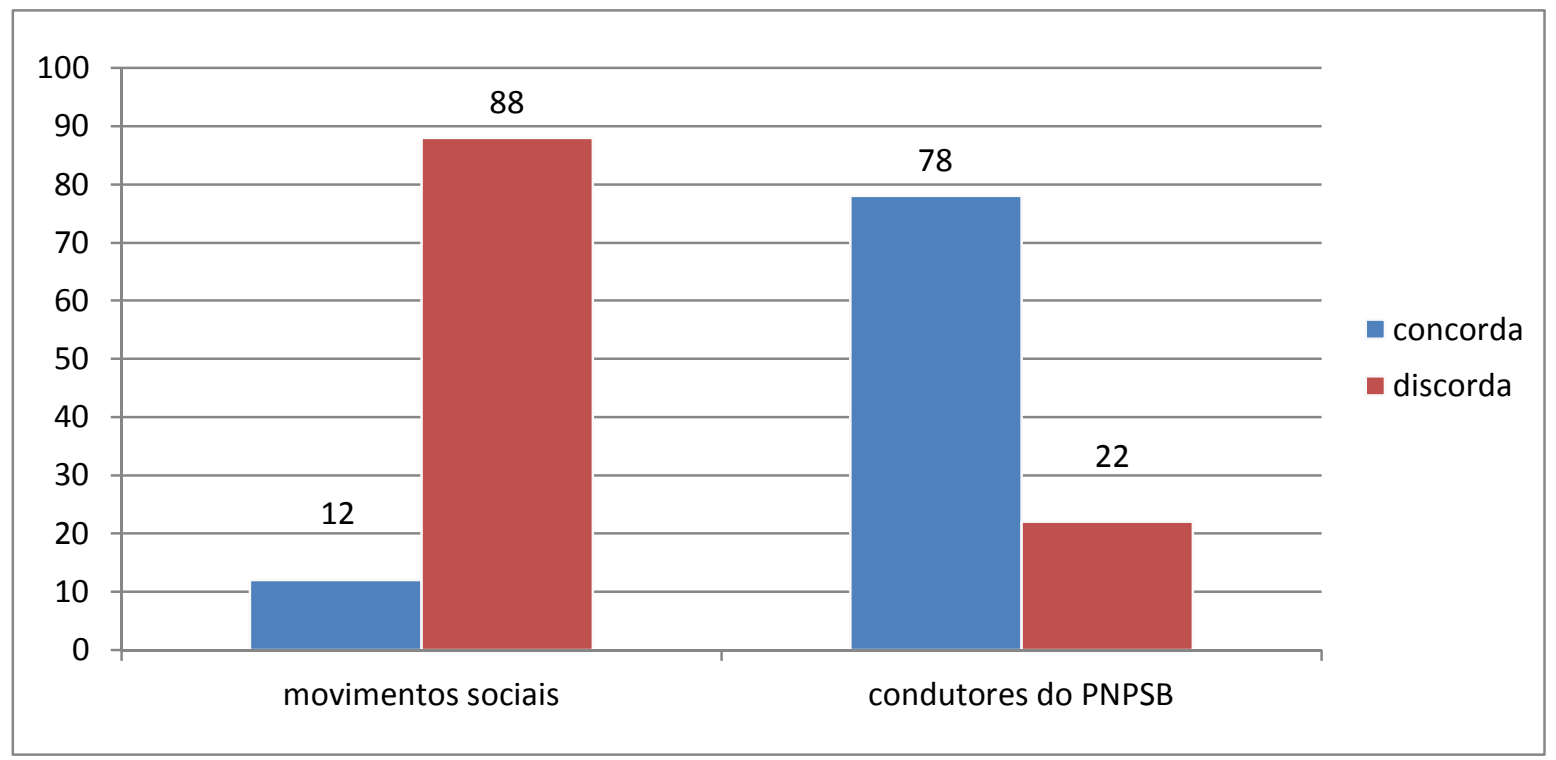

Fonte: Pesquisa de campo.

Os resultados obtidos com as organizações sociais apontaram que $12 \%$ concordam com prazo de execução do Plano e $88 \%$ discordam, devido à falta de regularidade nas ações, pois estas nem sempre acontecem na data planejada e os condutores dessa política demoram bastante tempo para realizá-las. Do total de condutores envolvidos, $78 \%$ concordam com o prazo de execução do Plano - e reforçaram que não há prazos determinados para a finalização do Plano de Sociobiodiversidade - está sendo construído de forma contínua em etapas. Mesmo com esse argumento, 22\% discordaram que o Plano esteja sendo executado dentro do prazo regular, porque a falta de planejamento de ações num intervalo de tempo menor seria o obstáculo. 
Gráfico 6 Opinião dos painelistas relacionada à disponibilidade das informações do plano no Portal da Comunidade da Sociobiodiversidade/MDA

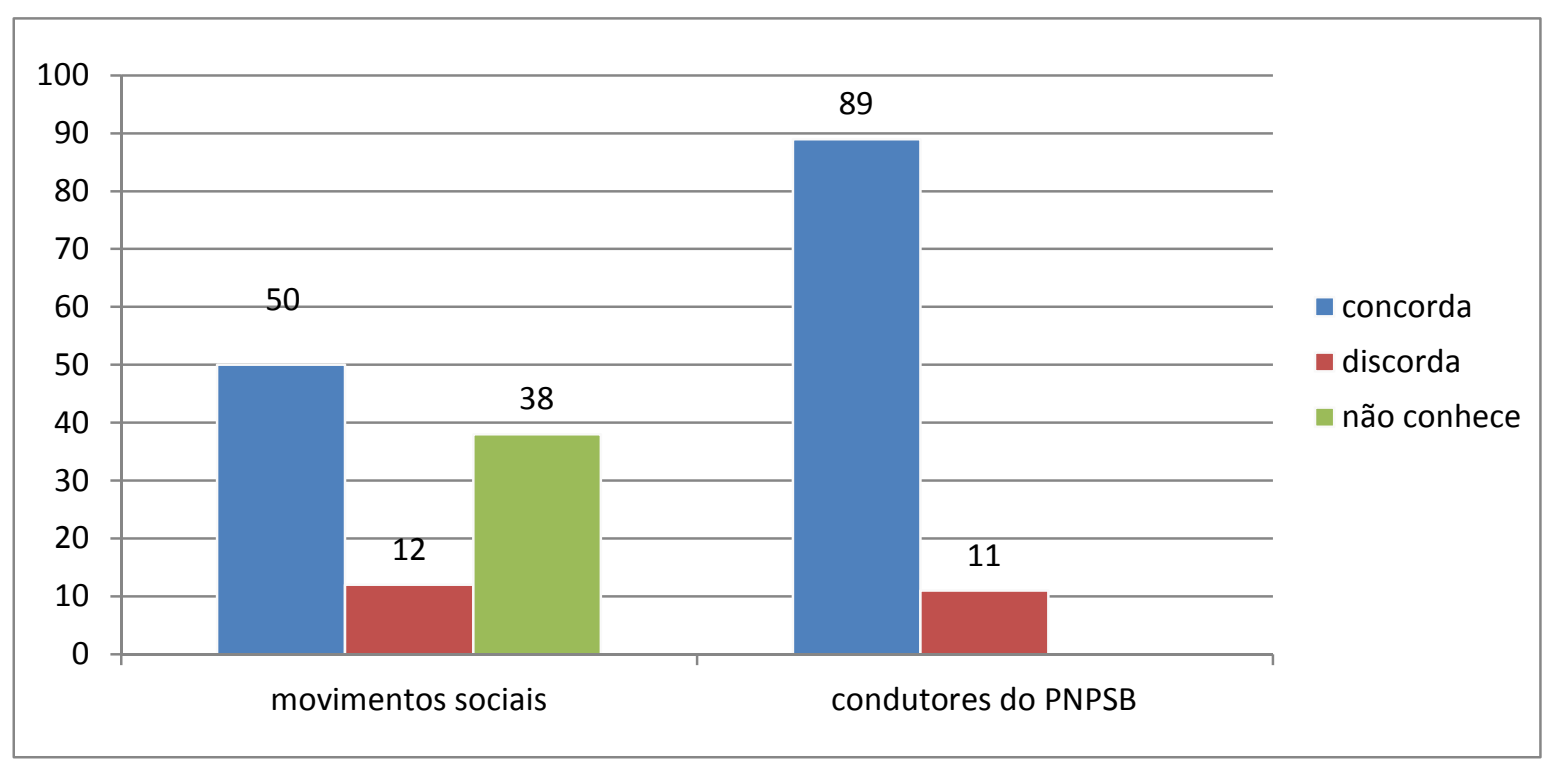

Fonte: Pesquisa de campo.

Para 50\% dos membros de movimentos sociais, as informações disponibilizadas no site do MDA são acessíveis, mas acrescentam que é também necessário o contato direto com pessoas responsáveis pela implementação do PNPSB, enquanto outros $12 \%$ desconhecem essas informações por meio da internet, porque consideram complicado o acesso, e 38\% informaram que nas suas comunidades não dispõem de acesso a internet. No resultado dos condutores do Plano, 89\% consideram acessíveis as informações do site do MDA, mas enfatizam que muitas organizações de base ainda não possuem acesso ao meio digital, sendo, portanto, fundamental criar outro instrumento mais popular com uma linguagem acessível para essas comunidades. E 11\% discordam da acessibilidade das informações no site do MDA (Gráfico 6). 
Gráfico 7 Opinião dos painelistas sobre a localização remota de várias comunidades extrativistas de babaçu, considerada como impedimento para os projetos com estes produtos

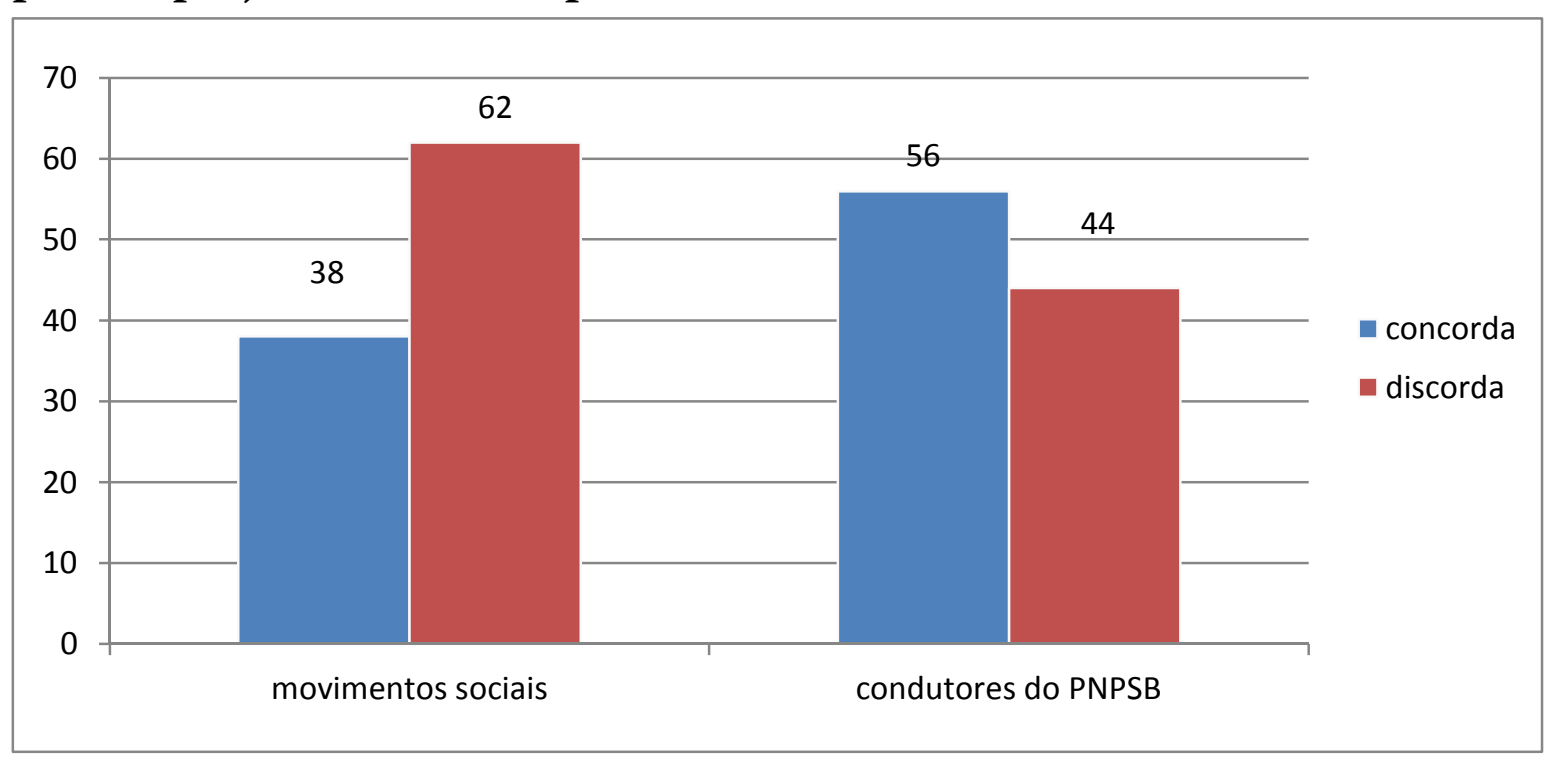

Fonte: Pesquisa de campo.

Os representantes dos movimentos sociais apontam um resultado no qual 38\% concordam com o fato da localização remota dificultar o desenvolvimento desses projetos, ressaltam que muitas vezes o produto fica armazenado e perde a validade, isso ocorre devido ao acesso ruim e à distância. Porém, $62 \%$ dessas organizações discordam que a localização remota de uma comunidade possa representar um empecilho no avanço de projetos através do coco de babaçu, e ainda consideram as questões burocráticas o principal obstáculo encontrado para inserir os produtos da agricultura familiar no mercado (Gráfico 7).

Dentre os condutores do Plano, 56\% consideram um entrave à localização distante de algumas comunidades extrativistas de babaçu e destacam que a partir do processo de organização das comunidades e de políticas públicas voltadas para o setor essas dificuldades serão dirimidas, e, portanto, os projetos serão realizados com eficácia. Entretanto, um percentual de $44 \%$ discorda dos demais, destacando que a falta de uma estratégia logística organizada favorece a inserção de atravessadores na cadeia produtiva, o que dificulta a melhoria dos ganhos dos extrativistas; no entanto, esse é um impedimento que pode ser diminuído se as condições de infraestrutura e logística forem planejadas através de políticas públicas ou parcerias com setor privado. Pois a distância dificulta a comercialização e encarece alguns custos, porém, existem estradas no Bico do Papagaio e o problema maior das comunidades extrativistas que trabalham com o coco de babaçu é a falta de transporte. 
Gráfico 8 Opinião dos painelistas referente às elevadas taxas de analfabetismo, consideradas como obstáculo na gestão de empreendimentos com produtos da sociobiodiversidade

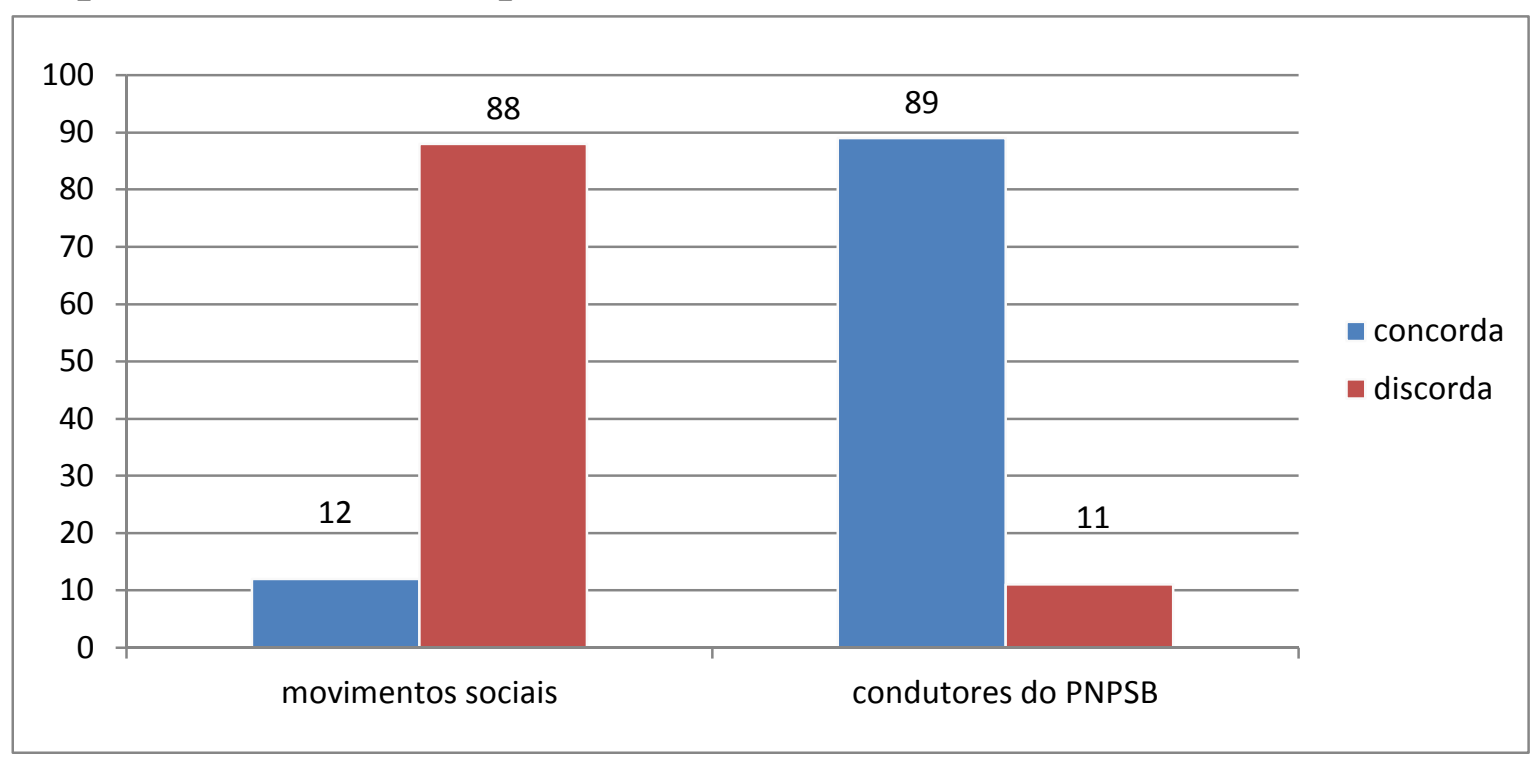

Fonte: Pesquisa de campo.

Em 88\% das respostas de movimentos sociais, as elevadas taxas de analfabetismo são obstáculo para a gestão de empreendimento com o babaçu, além de seus membros (quebradeiras) revelarem as dificuldades que tiveram para educar os filhos mais velhos, bem como, o impedimento no momento de realizar os cálculos para saber o resultado da comercialização de seus produtos (óleo, amêndoa, carvão). Outras $12 \%$ responderam que discordam da situação das elevadas taxas de analfabetismo impedir o desenvolvimento na gestão de projetos e empreendimentos por meio do babaçu (Gráfico 8).

Nas respostas, $89 \%$ dos condutores envolvidos consideraram que as elevadas taxas de analfabetismo impedem o bom desempenho nos referidos empreendimentos. Alguns depoimentos ressaltaram o analfabetismo como um impedimento para diversas atividades, daí a necessidade dos jovens terem acesso a uma escola que permita outras escolhas como as Casas Familiares Rurais ou Escolas Família Agrícola. Nas demais respostas, 11\% dos demais painelistas informam que discordam dessa situação gerada pelas elevadas taxas de analfabetismo. 
Gráfico 9 Opinião dos painelistas sobre á utilização do PAA (Programa de Aquisição de Alimentos da Agricultura Familiar) como mecanismo para ampliar o mercado de produtos e subprodutos do babaçu

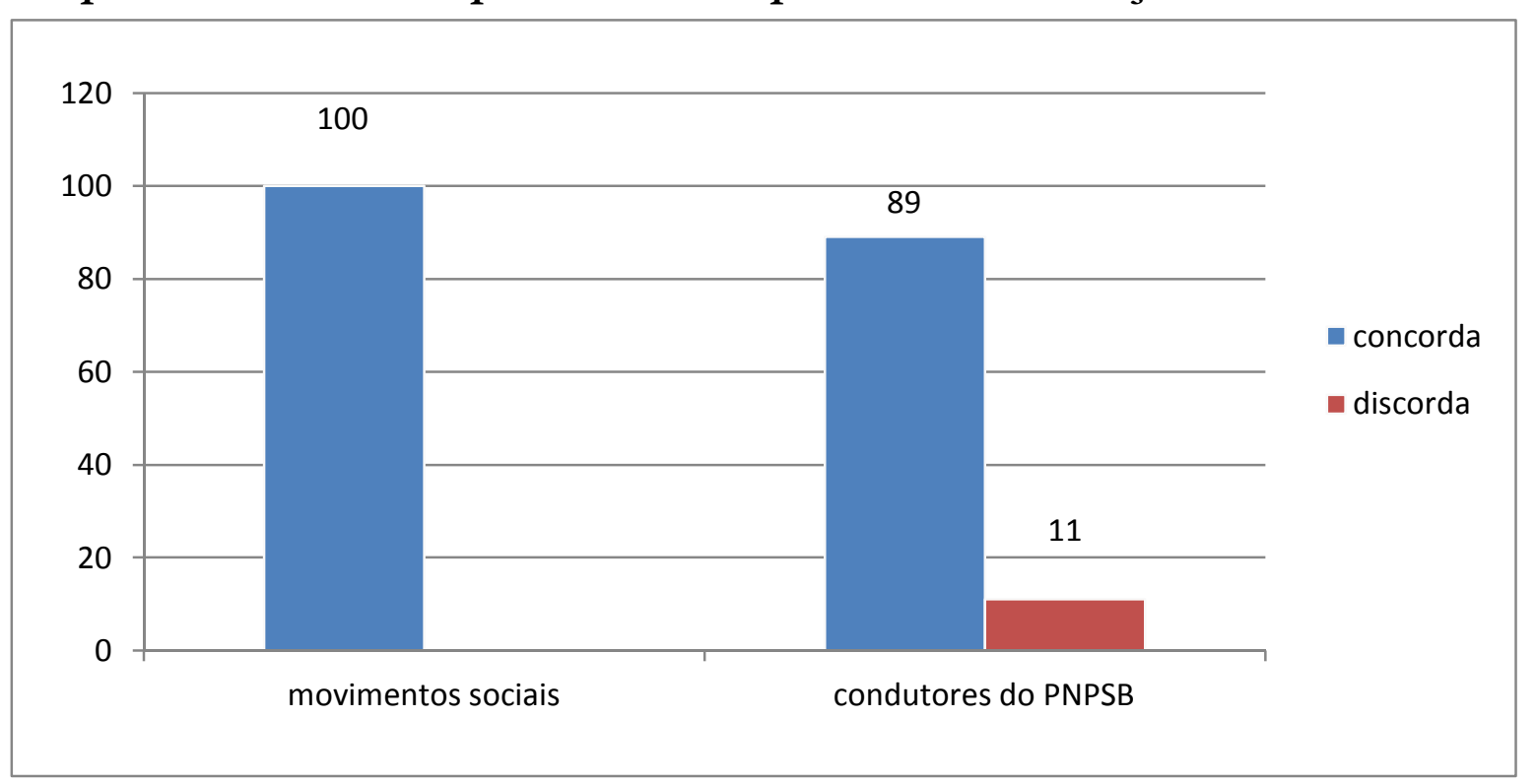

Fonte: Pesquisa de campo.

Os representantes dos movimentos sociais revelaram bastante interesse na articulação entre o Programa de Aquisição de Alimentos da Agricultura Familiar (PAA) e o PNPSB, pois 100\% destas acreditam que através da articulação dessas duas políticas poderão ampliar as oportunidades de mercado para os produtos do coco de babaçu. Enfatizaram que por meio da comercialização praticada com o apoio de recurso do PAA, os frutos não são desperdiçados, nem os produtos perdem a validade, além de comercializarem, entre si, com as outras associadas.

As respostas dos condutores envolvidos indicaram que $89 \%$ concordam com esse mecanismo, acrescentando que o acesso às políticas públicas de apoio à comercialização é o primeiro passo para a inclusão social e precisa ser estimulado. Contudo, $11 \%$ dos demais painelistas discordaram das possibilidades advindas desse mecanismo. 
Gráfico 10 Opinião dos painelistas referente às ações para o fortalecimento do processo de industrialização do coco de babaçu

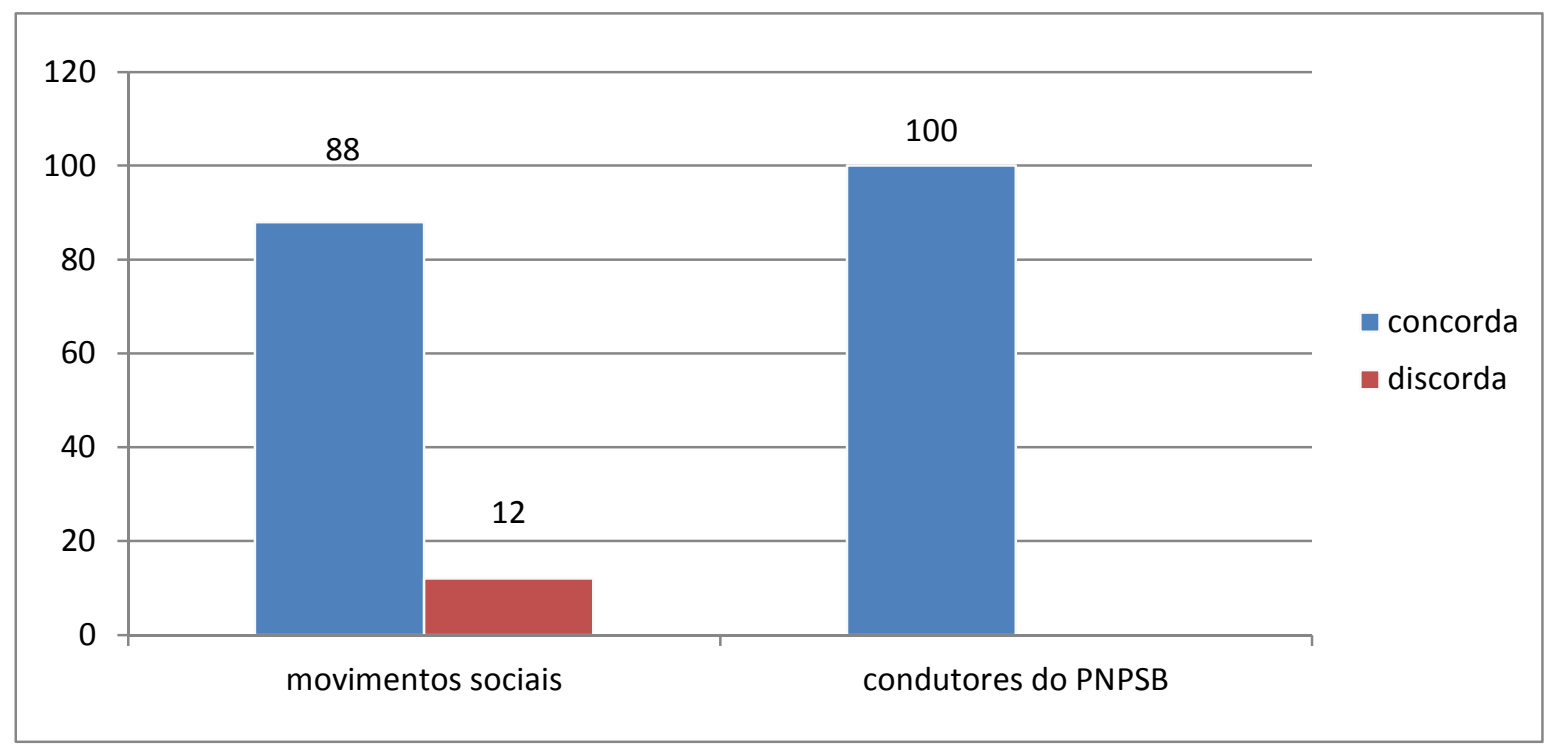

Fonte: Pesquisa de campo.

Nas respostas obtidas dos representantes dos movimentos sociais, 88\% concordam com as ações descritas para estruturar o processamento do coco de babaçu, mas ressaltam que, além do interesse nas inovações tecnológicas, o objetivo maior é manter as tradições culturais, pois, dessa forma, estarão garantindo a valorização de sua cultura. $\mathrm{Na}$ oportunidade, reafirmaram as dificuldades na concessão de certificação, selos e notas fiscais. Outros 12\% discordam dessas ações, sem nada a ponderar. O total de condutores do PNPSB envolvidos no resultado foi de $100 \%$ dos painelistas concordando com ações estruturais como o beneficiamento do produto como chave para alcançar bons resultados com o mercado de produtos da sociobiodiversidade.

\section{Sugestões para melhoria da implementação da Política}

A partir das entrevistas com líderes comunitários e com os atores institucionais condutores da política, foram elencadas as seguintes estratégias para melhorar sua implementação, com maior probabilidade de alcançar os resultados pretendidos:

i. Elaborar e executar um planejamento de comunicação que utilize vários veículos, como rádio comunitária, carro de som e impressos;

ii. Pleitear junto aos órgãos públicos a diminuição da burocracia em relação à implantação do Serviço de Inspeção Municipal (SIM) para comercialização de produtos; pedidos de licença de operação (LOP) junto ao NATURATINS (Instituto natureza do Tocantins); 
iii. Organizar a estrutura logística e ampliar o investimento em rodovias e sistemas de transportes;

iv. Estimular a organização social e produtiva entre os extrativistas;

v. Ampliar e viabilizar o acesso às políticas públicas;

vi. Divulgar para a população (consumidores potenciais) os benefícios nutricionais do coco de babaçu, com vistas a estimular o consumo dos produtos da sociobiodiversidade;

vii. Promover o reconhecimento e a valorização do extrativismo do babaçu como forma de conservação ambiental;

viii. Definir, como ação prioritária do Governo Federal, o combate às elevadas taxas de analfabetismo que atingem muitas comunidades extrativistas.

\section{Conclusão}

A presente pesquisa revelou que o PNPSB representa uma oportunidade para as comunidades extrativistas colocarem suas demandas sociais e comercializarem os seus produtos, abrangendo segmentos econômicos que antes não seriam contemplados. A maior parte dos extrativistas envolvidos almeja a implementação efetiva desta política pública e das suas ações (assistência técnica e extensão rural; fomento, credito e incentivos fiscais; pesquisa e desenvolvimento tecnológico; marco regulatório; divulgação e comunicação), voltadas para contribuir com e promover, de fato, o fortalecimento da cadeia produtiva do babaçu.

Neste sentido, atender as sugestões apresentadas pelos líderes comunitários e atores institucionais condutores para a melhoria da implementação do Plano, acima citadas, será fundamental para ampliar o alcance do Plano do Nacional da Sociobiodiversidade, estendendo-o às comunidades extrativistas de toda a região do Bico do Papagaio.

\section{Referências}

BARBOSA JÚNIOR, Odilon Arruda. Coco Babaçu: potencial extrativista e industrial na região do Bico do Papagaio, Estado do Tocantins. 92 f. Monografia (graduação). Universidade Federal do Tocantins, Campus de Tocantinópolis, Curso de Pedagogia, Tocantinópolis/TO, 2008.

DENCKER, Ada Freitas; DA VIA, Sarah Chucid. Pesquisa empírica em ciências humanas (com ênfase em comunicação). São Paulo: Futura, 2001. 
DOURADO, Josilene de Jesus. Das quebradeiras de coco à Tobasa: O processo do babaçu a Tobasa e da vida na Região Amazônica. 80 f. Monografia (graduação). Universidade Federal do Tocantins, Campus de Tocantinópolis, Curso de Pedagogia, Tocantinópolis/TO, 2007.

FIGUEIREDO, Argelina Maria Cheibub; FIGUEIREDO, Marcus Faria. Avaliação política e avaliação de políticas: um quadro de referencia teórica. Análise e Conjuntura, Belo Horizonte, 1 (3), p. 107-127, set./dez., 1986.

ORMOND, José Geraldo Pacheco. Glossário de termos usados em atividades agropecuárias, florestais e ciências ambientais. Rio de Janeiro: BNDES, 2006.

GIOVINAZZO, Renata A. Modelo de aplicação da metodologia Delphi pela internet: vantagens e ressalvas. Administração On Line, v. 2, n. 2, 2001.

WRIGHT, James Terence Coulter; GIOVINAZZO, Renata Alves. Delphi: uma ferramenta de apoio ao planejamento prospectivo. Caderno de pesquisas em Administração, São Paulo, v. 1, n. 12, p. 54-65, 2000.

SACHS, Ignacy. Desenvolvimento includente, sustentável, sustentado. Rio de Janeiro: Garamond, 2008.

MAY, Peter Herman. Palmeiras em chamas: transformação agrária e justiça social na zona do babaçu. São Luís, EMAPA/FINEP/Fundação Ford, 1990.

RUA. Maria das Graças. Análises de políticas públicas: conceitos básicos. Disponível em: http://franciscoqueiroz.com.br/portal/phocadownload/gestao/ rua $\% 20$ maria $\% 20$ \%20analisedepoliticaspublicas.pdf. Acesso em: 15 fev. 2011.

Endereço para correspondência:

Lucélia Neves dos Santos - luceliadr@gmail.com Avenida NS 15, 109 Norte, Plano Diretor Norte

77001-090 Palmas/TO, Brasil

Waldecy Rodrigues - waldecy@terra.com.br

Avenida NS 15, 109 Norte, Plano Diretor Norte

77001-090 Palmas/TO, Brasil 